Regards sur l'économie allemande

Bulletin économique du CIRAC

$95 \mid 2010$

Varia

\title{
Métallurgie : partenaires sociaux responsables
}

\section{Isabelle Bourgeois}

\section{OpenEdition \\ Journals}

Édition électronique

URL : http://journals.openedition.org/rea/4036

DOI : $10.4000 /$ rea.4036

ISBN : 978-2-8218-0886-7

ISSN : 1965-0787

Éditeur

CIRAC

Édition imprimée

Date de publication : 1 mars 2010

Pagination : 37-38

ISSN : 1156-8992

Référence électronique

Isabelle Bourgeois, " Métallurgie : partenaires sociaux responsables », Regards sur l'économie allemande [En ligne], 95 | mars 2010, mis en ligne le 01 mars 2012, consulté le 15 septembre 2020. URL : http://journals.openedition.org/rea/4036

Ce document a été généré automatiquement le 15 septembre 2020

(C) CIRAC 


\title{
Métallurgie : partenaires sociaux responsables
}

\author{
Isabelle Bourgeois
}

\section{Accord-pilote dans la métallurgie en Rhénanie du Nord-Westphalie}

1 Le 18 février, le syndicat de la métallurgie IG Metall et son partenaire patronal Gesamtmetall ont conclu à Düsseldorf un accord-pilote pour la Rhénanie du NordWestphalie qui prendra effet le $1^{\text {er }}$ avril et expirera le 31 mars 2012. Il couvre les 700000 salariés de l'industrie métallurgique et électrique que compte cette branche dans le Land et servira de modèle aux accords conventionnels signés au niveau de la même branche dans les autres régions et Länder d'Allemagne.

L'accord, dénommé « Paquet de crise 2012 » (Krisenpaket 2012), comprend trois volets :

\section{- Salaires :}

- les conventions salariales expirant fin mars sont prorogées pour 11 mois ;

- le $1^{\mathrm{er}}$ mai et le $1^{\mathrm{er}}$ décembre 2010 sera versée une prime de $160 €$ à chaque fois (60€ pour les apprentis) ;

- le $1^{\text {er }}$ avril 2011, les salaires conventionnels seront augmentés de 2,7\% (pour une durée de 12 mois); des accords d'entreprises peuvent, le cas échéant, prévoir d'avancer ou de reculer de deux mois cette hausse.

\section{- Emploi :}

- la nouvelle convention "L'avenir en emploi » (Zukunft in Arbeit, ZiA) s'appliquera aux entreprises qui recourent au chômage partiel depuis au moins 12 mois; elle vise à préserver les salariés d'un licenciement économique. Dans une première phase (au moins 6 mois), les coûts du chômage partiel sont réduits de la manière suivante : les primes de congé et la prime de Noël sont mensualisées, ce qui donne un coût de pouce aux salariés et réduit les charges des employeurs qui n'ont à verser ces primes que pour les heures effectivement travaillées. Dans un second temps (12 mois), la durée de travail hebdomadaire peut être abaissée de 35 à 28 heures, avec compensation partielle dès la $31^{\mathrm{e}}$ heure travaillée. Cette réduction ne se 
fait que sur la base d'un engagement volontaire; elle est une proposition alternative au chômage partiel prévu par la loi ;

- les apprentis peuvent prétendre à l'embauche dans l'entreprise formatrice au bout de 12 mois.

- Formation :

Une nouvelle convention «L'avenir dans la formation » (Zukunft in Bildung) crée un cadre qui régule, sur le modèle de la retraite progressive, la rémunération du temps consacré à la formation continue.

\section{Un accord qui repose sur la confiance mutuelle}

2 Cet accord est historique : les salariés renoncent à une augmentation des salaires en 2010, en contrepartie d'une garantie de l'emploi assortie de dispositions permettant aux entreprises de faire face aux difficultés qu'elles traversent. Ce qui le caractérise, c'est la profonde confiance mutuelle qu'il révèle entre les partenaires sociaux. Car les dispositions innovantes (date d'effet de la hausse des salaires, réduction du temps de travail, formation continue) reposent sur une base volontaire. Il confirme par ailleurs la compréhension foncière qu'a des lois de l'économie ou de l'état de la conjoncture le plus grand syndicat unitaire de branche allemand (2,3 millions d'adhérents). Cela n'a pas toujours été le cas, notamment lors de la précédente hausse contractuelle des salaires (près de $3 \%$ en moyenne), conclue à l'issue d'une période de forte croissance et placée sous le signe de la redistribution des richesses. Mais dans cette récession historique, IG Metall a prouvé qu'il assume les responsabilités macro-économiques que confère aux partenaires sociaux la Constitution allemande.

\section{IG Metall : conscience des enjeux macro-économiques}

Dans un communiqué du 8 février par exemple, où IG Metall expose ses revendications, il explique son opposition à une "zéro augmentation", avant de poursuivre: "pour stabiliser l'économie, il faut donner un coup de pouce au pouvoir d'achat -grâce à la sécurité de l'emploi et par des salaires plus élevés ». La sécurité de l'emploi est certes priorité absolue ; or imposer aux employeurs une hausse notable des salaires met en danger les entreprises fragilisées par la récession, et donc l'emploi. Pour éviter cette situation, il faut trouver un compromis "win-win". Dans le même communiqué, le syndicat expliquait même en forçant quelque peu le trait : «la Bundesbank a remis une sourdine à l'espoir d'une reprise: le léger frémissement s'est à nouveau affaibli, déclare-t-elle. Dans cette situation, l'objectif prioritaire pour IG Metall reste d'épuiser toutes les possibilités pour éviter les licenciements ». Et il publie des statistiques officielles permettant de comprendre en un clin d'œil «l'impact de la crise sur l'industrie des métaux et de l'électricité en 2009 »: en moyenne mensuelle, 741000 salariés étaient en chômage partiel (janvier-novembre 2009), ce qui correspond à 230188 emplois en équivalent temps plein; d'octobre 2008 à octobre 2009, les entreprises de plus de 20 salariés ont supprimé 183000 emplois.

\section{Un accord conjoint de gestion de crise...}

Berthold Huber, premier secrétaire d'IG Metall, salue cet accord prouvant qu'a pu être négociée "une répartition des charges équitable». De son côté, Martin Kannegiesser, 
président de Gesamtmetall, souligne que "cet accord est la preuve patente d'une gestion de crise conjointe». Et il ajoute : "à l'issue d'intenses négociations, nous sommes parvenus, deux mois avant la date d'expiration des conventions tarifaires, à la conclusion d'un accord - et qui plus est par une voie pacifique, ce qui n'avait jamais encore été le cas» (communiqués du 18-02).

\section{... qui révèle une approche modernisée des accords de branche}

5 Cet accord révèle non seulement que le "modèle " de la convention tarifaire de branche, qu'on pensait à l'agonie, est au contraire bien vivant, du moins dans l'industrie, métallurgie en tête, qui présente encore un fort degré d'organisation. IG Metall, en tout cas, a su, ces dernières années, moderniser la macro-régulation sociale au niveau de sa branche et apporter aux entreprises la flexibilité requise qui a grandement contribué, dans la récession actuelle, à stabiliser le marché de l'emploi ; les droits des salariés s'en sont trouvés d'autant mieux protégés. C'est dans le prolongement des réflexions engagées dès 2002 sous la direction de B. Huber (alors numéro deux du syndicat) avec ses homologues patronaux sur un nouvel équilibre à trouver entre les deux échelons de négociation que sont la branche et l'entreprise, qu'ont ainsi pu être adoptées aujourd'hui des solutions constructives pour contribuer à la sortie de crise. C'est là que réside l'exemplarité de l'accord conclu en Rhénanie du Nord-Westphalie. "Nous avons assumé notre responsabilité macro-économique en tant que la plus importante branche industrielle d'Allemagne", résume M. Kannegiesser (communiqué du 18-02). "Les partenaires sociaux ont fait du bon travail », conclut pour sa part B. Huber (Handelsblatt, 26-02).

6 Les acteurs économiques - syndicats et patronat - ont apporté leur contribution. Au gouvernement maintenant d'apporter la sienne, soulignent-t-ils tous les deux. Pour que la nouvelle convention "L'Avenir en emploi » puisse développer ses effets stabilisateurs, il faut que le législateur prolonge la durée des dispositions particulières adoptées pour le chômage partiel pendant la récession et continue d'exonérer de cotisations sociales les indemnités de chômage partiel (elles sont prises en charge par l'Agence fédérale pour l'emploi jusqu'à la fin 2010). Que cette revendication aboutisse ou non, l'accord montre en tout cas que le "modèle rhénan » est loin d'être dépassé : les acteurs économiques et sociaux assument leurs responsabilités à leur niveau, au gouvernement d'adapter les conditions cadre aux besoins de l'économie. (IB)

\section{INDEX}

Mots-clés : accord salarial, conditions de travail, dialogue social, emploi, formation, IG Metall, industrie métallurgique, Land, Länder, métallurgie, négociation collective, partenaires sociaux, politique contractuelle, région, revenu, Rhénanie du Nord-Westphalie, salaire, syndicat 